\title{
Víctimas de violencia de género mayores de sesenta y cinco años: análisis interseccional de vulnerabilidades y nuevas formas de maltrato
}

\section{Mentxu Hernando Gómez}

\author{
Universidad de Deusto \\ mentxu.hernando@opendeusto.es
}

\section{Teresa Laespada \\ Universidad de Deusto \\ laespada@deusto.es}

Genero indarkeriaren biktima diren 65 urtetik gorako emakumeen errealitatean, haien ezkutaketan eta iraunaraztean eragina duten alderdi psikosozial batzuk elkartzen dira. Zirkunstantzia horrek talde honen alderdi diferentzialak osatzen ditu, bere ikuspunturako kontuan hartu behar direnak. Adin aldagaia eta intersekzionalitatearen printzipioa esparru intimoan genero indarkeriaren analisian sartzea oinarrizkoak dira adineko emakumeek jasaten duten indarkeriaren ikusezintasuna ulertzeko. Artikulu honek aurrerapenak erakusten ditu, emakumeen talde honetan gurutzatzen diren alderdien eta inguruabarren ikusgarritasunaren inguruan, hala nola, identitatea, mendekotasunak, adineko emakumearen egungo eginkizun soziala, zaintzaren etika, edadismoa edo beste indarkeria mota batzuekin bat egitea, baita ahultasun-

dimentsio handiagoak sortzen dituzten haien artean funtzionatzen duten harremanak ere. Azkenik, profesionalek eta gizarte osoak ditugun erronkak ebakitzen dira intersekzionalitatearen printzipio babes tresna gisa aplikatzeko.

\section{GAKO-HITZAK:}

Adineko emakumeak, genero-indarkeria, indarkeria matxista, biktimak, intersekzionalitatea, adina.
En la realidad de las mujeres mayores de sesenta y cinco años víctimas de violencia de género, interseccionan una serie de aspectos psicosociales que inciden en su ocultación y perpetuación. Esta circunstancia conforma los aspectos diferenciales de este colectivo que deben ser tenidos en cuenta para su abordaje. La inclusión de la variable edad y el principio de interseccionalidad en el análisis de la violencia de género en el ámbito de pareja son fundamentales para comprender la invisibilidad de la violencia que sufren las mujeres mayores. Este artículo muestra los avances realizados en torno a la visibilización de los aspectos y circunstancias que interseccionan en este grupo de mujeres, tales como la identidad, las dependencias, el rol social actual de la mujer mayor, la ética del cuidado, el edadismo o la confluencia con otras violencias, así como las relaciones que operan entre ellos, los cuales generan mayor vulnerabilidad. Por último, se perfilan los retos que de los profesionales y la sociedad en su conjunto para aplicar el principio de interseccionalidad como herramienta de protección.

\section{Palabras Clave:}

Mujeres mayores, violencia de género, violencia machista, víctimas, interseccionalidad, edad. 


\section{Introducción}

A lo largo de los siglos XX y XXI, las leyes han ido modificando, tanto con carácter nacional como autonómico, la situación de la mujer a favor de erradicar las formas de violencia machista, la cual estaba presente de forma legitimada, en la época en que fueron socializadas las mujeres mayores de sesenta y cinco años. Ahora bien, algunas víctimas de edades avanzadas fueron sometidas y recluidas en el ámbito privado, accediendo al matrimonio bajo una realidad patriarcal machista, por lo que han tenido poco margen de maniobra para beneficiarse de estos avances por erradicar esta lacra, y esta forma de violencia se ha podido mantener en su contexto durante décadas, lo que implica un daño profundo para estas mujeres y una fuerte resignación e indefensión ante la situación. En otras palabras, han quedado excluidas de todos sus derechos más elementales.

En este artículo se aborda la situación diferencial de las víctimas de violencia machista en el ámbito de pareja mayores de sesenta y cinco años desde la perspectiva de la interseccionalidad, la cual garantiza una mirada inclusiva, extensa y equitativa. Un acercamiento interseccional conlleva, además, analizar la relación entre los diferentes espacios sociales donde se manifiestan, refuerzan o superponen los procesos de esta violencia.

Su objetivo, por tanto, es trascender el poder descriptivo y sumativo de cuantas adversidades atraviesan a una víctima mayor de sesenta y cinco años, para fijarse en cómo cada una de las experiencias de una persona es fruto de la interacción de muchas estructuras sociales y contextuales, y las relaciones que operan en estas interacciones. Para ello, se muestran avances en la revisión en torno al estado de la cuestión ${ }^{1}$ sobre los aspectos y circunstancias que confluyen en la situación de victimización de estas mujeres mayores circundantes a la variable edad. Una mirada ampliada e interseccional mostrará por tanto cómo se sitúa la víctima frente a esta violencia, cómo se manifiesta este maltrato y sus consecuencias para la mujer, y ayudará a comprender la influencia del entorno social e institucional en términos de atención a esta realidad concreta. Las mujeres mayores que sufren violencia son sujetos de derechos en nuestra sociedad y, por tanto, se hace necesario que sean objeto de una atención conforme a la interseccionalidad de su situación. Sus necesidades merecen formar parte de las agendas de las políticas sociales, contribuyendo así a erradicar esta violación de los Derechos Humanos.

${ }^{1}$ Se hace referencia a la revisión realizada como parte del proceso de tesis doctoral en curso "Análisis crítico del abordaje de la situación de violencia de género en mujeres mayores de 65 años en la Comunidad Autónoma del País Vasco. Contribuciones para una intervención adaptada a su realidad", que se desarrolla en el marco del Programa de Doctorado en Educación de la Universidad de Deusto.
El artículo se estructura con una parte inicial que contextualiza la perspectiva interseccional en materia de violencia de género, para dar paso a analizar descriptivamente la violencia de género en mujeres mayores, tanto de forma cualitativa como cuantitativa, así como la invisibilidad de esta violencia, que victimiza aún más a las mujeres mayores de sesenta y cinco años. A continuación, se muestran los aspectos claves que interactúan en la realidad de la mujer mayor, víctima de violencia de género, los cuales nos brindarán una radiografía intereseccional de la situación y su complejidad. Por último, se perfilan ciertas claves que pueden ayudar a afrontar este reto.

\section{Interseccionalidad}

La interseccionalidad ha sido definida como una de las contribuciones más importantes de la teoría feminista a las ciencias sociales y como un nuevo campo de investigación (McCall, 2005; Cho et al., 2013). Es el principio de apertura a las diferencias (Purtschert y Meyer, 2010). Se trata de un concepto analítico introducido por Kimberlé Crenshaw en la Conferencia Mundial contra el Racismo en Sudáfrica en 2001. Parte de la existencia de categorías, biológicas, sociales o culturales, como la raza y el género, que no influyen igual en todas las personas. Existe una estructura primaria donde, además de estas categorías señaladas, permanecen otras desigualdades, las cuales interaccionan entre sí en múltiples y simultáneos niveles y, a su vez, de forma diferente en cada situación personal y/o grupo social, mostrando diferentes estructuras de poder. Hace referencia a los distintos vectores de vulnerabilidad que atraviesan la vida de las personas y sociedades, sean estas estructurales o coyunturales y que pueden cruzarse en colectivos o personas lo que incrementa de forma exponencial los efectos de cada vector. Crenshaw (2000) hacía una llamada a prestar atención a las "diferencias que hacen la diferencia” en las distintas formas en que varios grupos de mujeres experimentan la discriminación de género. Esta circunstancia no puede ser visualizada como una suma de categorías, puesto que la situación de desventaja interacciona con las vulnerabilidades preexistentes, produciendo una dimensión diferente de desempoderamiento (Crenshaw, 2002).

En este sentido, tal y como señala Sleap (2017), la discriminación puede basarse en una serie de características diferenciales, que pueden ser comunes entre diversas mujeres o incluso específicas. Distingue la discriminación interseccional (intersectional) como aquella que se basa en una combinación de dos o más características diferentes, por ejemplo, edad, género y discapacidad. La combinación crea una forma única de discriminación que sufre cada mujer y debe ser tenida en cuenta para comprender las intervenciones a desarrollar, según edades, según discapacidades o según intensidades, presencias o ausencias de 
determinadas variables. Según esta misma autora, la discriminación puede ser acumulativa. En este caso, se acumulan los efectos de la discriminación de forma repetida en el tiempo o en contextos distintos. Se denomina también "discriminación aditiva”.

Por ello, la perspectiva de la interseccionalidad es la herramienta analítica que permite conocer mejor la violencia que sufren las mujeres cuando se acumulan o interactúan distintas características discriminatorias. Es útil para conocer con más exactitud el nivel de impacto que producen ciertas situaciones de desigualdad unidas a la situación de violencia machista que sufren las mujeres mayores de sesenta y cinco años en función de una serie de variables diferenciales, así como las interacciones entre ellas. Y, sobre todo, ayuda a responder a la cuestión de en qué medida esas relaciones diferentes de vulnerabilidad o desigualdad se pueden entender en términos de perdida de agencia y empoderamiento.

Pero no solo debe tenerse en cuenta como herramienta analítica. El abordaje interseccional es imprescindible en la intervención social con mujeres puesto que el conocimiento de todas las variables de discriminación que operan permite enfocar el abordaje y acercamiento a la situación de cada mujer. Por eso, a efectos de este artículo se considera al conjunto de víctimas de violencia de género en el ámbito de pareja como un sistema macro, siendo las mujeres mayores un sistema micro, dentro de esta totalidad. Comenzamos mostrando la invisibilidad transversal de este colectivo de víctimas.

\section{Invisibilidad: razones de la invisibilidad}

Las mujeres mayores que sufren violencia de género han permanecido ocultas y ocultadas, han sufrido una invisibilidad social. Comenzamos desgranando el porqué de estos dos aspectos.

\subsection{Víctimas ocultas}

Las mujeres mayores que sufren violencia han permanecido ocultas porque - entre otras razonesno ha existido conciencia de la violencia ante las múltiples acciones que el hombre, a lo largo de los años, ha ido sosteniendo sobre la mujer. Esto se debe, como indica Celdrán (2013), a diferentes factores explicativos relacionados fundamentalmente con la edad y la perspectiva de género, la cual influye negativamente en la forma de entender y actuar frente a esta violencia. La escasa conciencia sobre la violencia que sufren las mujeres mayores y la ausencia de marco referencial sobre esta violencia en edades avanzadas hace que ni ellas mismas ni su entorno sean capaces de resignificar las humillaciones, desprecios, violencia psicológica e incluso sexual. Es señalable respecto a esta última cuestión que muchas agresiones sexuales han sido consideradas el débito conyugal al que la mujer estaba obligada en el seno del matrimonio, por lo que las violaciones y agresiones sexuales en la pareja solo han sido identificadas como tales en los últimos años, siendo, por tanto, tolerado este maltrato en silencio, bien por se ha padecido desde tiempo atrás, bien porque se identifica con los roles y estereotipos de género acuñados durante muchos años. En muchos entornos, incluso hijas e hijos o familiares no consideran que el trato o ciertas acciones sean violencia y se excusan o justifican por la personalidad del agresor, exceso de consumo de alcohol, bravura del agresor, etc.

Uno de los rasgos diferenciales más destacados de la violencia de género contra las mujeres mayores es la persistencia en el tiempo. Hay estudios (Meneses-Falcón y Charro-Baena, 2019) que ya mencionan la larga y dura historia de agresiones y humillaciones que se inicia incluso antes de casarse, y esta continuidad en el abuso sigue siendo una característica de este tipo de violencia; su propia ocultación es propiciada por una minusvaloración de la importancia, la propia vergüenza o culpabilidad de la víctima incluso cuando son parejas que no se han formado en la juventud. Han permanecido y permanecen ocultas.

\subsection{Violencia ocultada}

Hasta principios de este siglo no se han comenzado a llevar a cabo investigaciones centradas en violencia perpetrada por compañero íntimo en mujeres mayores, como indican diferentes autores (Mouton et al., 2010; Fisher et al., 2003; Bonomi et al., 2007). Hasta hace relativamente poco tiempo, ha permanecido difuminada entre otros tipos de violencia, como es, sobre todo, el maltrato a las personas mayores ${ }^{2}$. Las investigaciones, e incluso las estadísticas oficiales, interrumpen la toma de datos en los sesenta y cinco y más años, haciendo la mayor parte de las veces prácticamente imposible realizar tareas de investigación con datos que superen esa edad. Esta falta de estudios específicos, con muestras de mujeres mayores que enfrentan violencia, tiene como resultado que no se oiga su voz; este efecto silenciador es otra forma de violencia añadida a la propia victimización. La propia agrupación en una sola categoría de edad "mayores de sesenta y cinco años" y considerar a todo el colectivo como un grupo homogéneo y único, oculta realidades muy diversas.

A pesar de la escasez de estudios específicos de prevalencia de violencia de género en mujeres mayores, podemos afirmar que en los estudios existentes se constata su existencia, así como en las encuestas a población general. En los estudios específicos que desarrolla la Delegación de Gobierno

${ }^{2}$ En un estudio financiado por el Ministerio de Educación y Cien cia, realizado por María Teresa Bazo (2001) en varias comunidades autónomas españolas, ya se detectó un 4,7\% de ancianos maltratados; en el $81 \%$ de los casos, las víctimas eran mujeres. 
Tabla 1. Prevalencia de violencia infligida en mujeres tanto por la pareja actual como la pasada, según la edad y tipo de violencia, y prevalencia del miedo en España, en 2015 y 2019 (cifras en porcentajes)

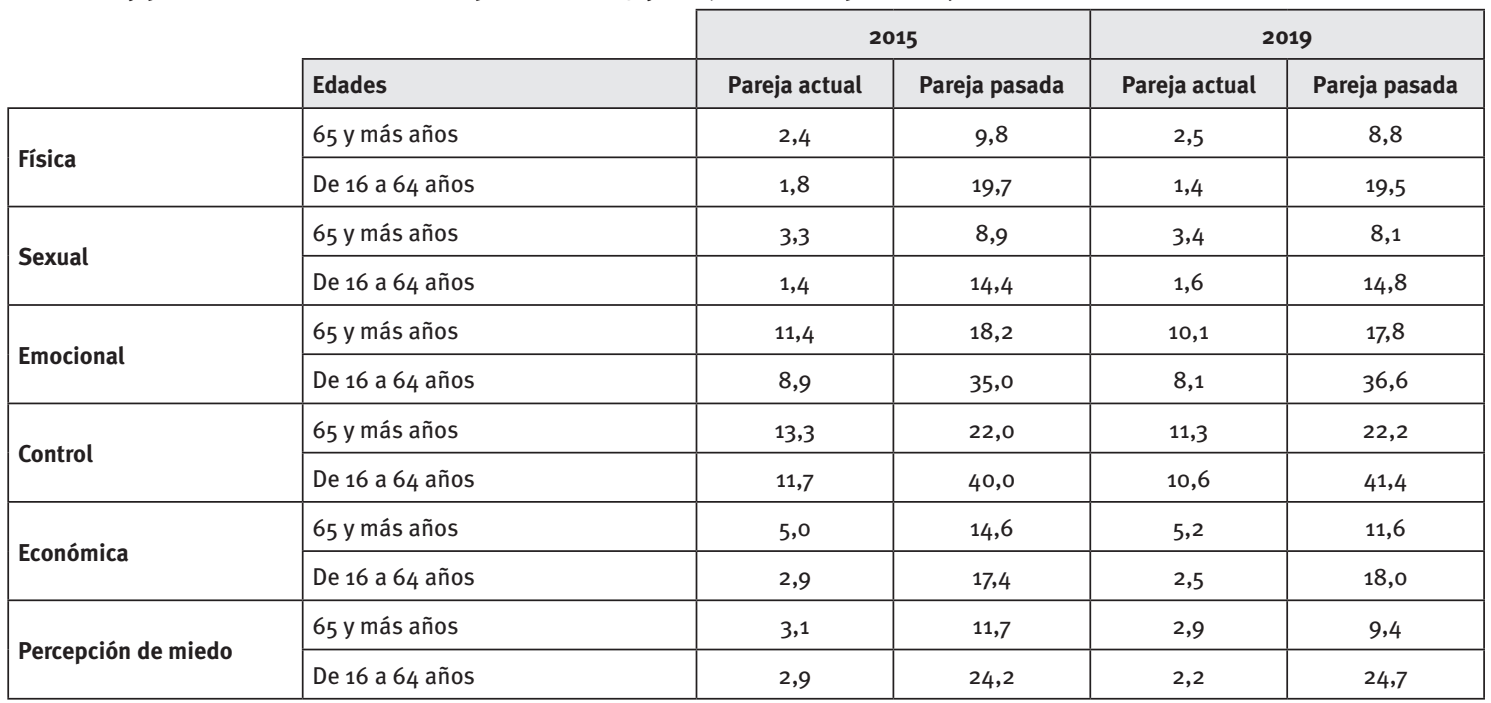

Fuente: Elaboración propia a partir de De Miguel Luken (2015) y Delegación del Gobierno para la Violencia de Género (2020).

para la Violencia de Género, ya en la encuesta del año 2015, y hasta el último de 2019, se evidencia que las mujeres mayores de sesenta y cinco años perciben sufrir violencia de género por parte de su pareja actual en mayor medida que las mujeres menores de sesenta y cinco años ${ }^{3}$ (Tabla 1).

Es reseñable la estabilidad de los datos comparando el año 2015 y 2019 en todas las edades y tipos de violencia, ya que la fotografía permanece estable entre ambos periodos de tiempo. Todos los indicadores presentados para medir las tipologías diversas de violencia señalan una mayor prevalencia de todo tipo de violencia en las mujeres mayores con sus parejas actuales que las mujeres de edad inferior a los sesenta y cinco años, y este indicador se muestra con igual estabilidad en los años 2015 y 2019. La violencia de control (11,3\%) y la violencia emocional $(10,1 \%)$ son las más prevalentes en las mujeres mayores con sus parejas actuales, pero hay una mayor violencia física $(2,5 \%)$ y sexual $(3,4 \%)$ sufrida entre estas mujeres que entre las mujeres más jóvenes, y son las grandes invisibilizadas en las intervenciones públicas y privadas ${ }^{4}$.

3 En 2015, la macroencuesta realizada por la Delegación de Gobierno para la Violencia de Género aplicó en cuestionario a un total de 10.171 mujeres, de las cuales $\mathbf{2 . 3 7 6}$ eran mujeres mayores de sesenta y cinco años. Se siguieron los criterios establecidos por la Delegación de Gobierno (De Miguel Luken, 2015). De Miguel Luken (2015) establece que hay violencia si se da alguno de estos comportamientos (malos tratos físicos, sexuales, emocionales, comportamientos de control y maltrato económico) por la pareja o expareja en los últimos doce meses. En las encuestas, la violencia se mide de forma estandarizada al objeto de reducir sesgos. No obstante, si nos amparamos en lo que Beaulaurier (2007) resalta sobre la convicción de que determinadas cuestiones son privadas y no deben airearse, cabría encontrarnos una infrarrepresentación de la violencia en mujeres mayores en comparación con mujeres más jóvenes. Con todo y con ello, si nos fijamos en la referencia temporal "a lo largo de la vida", este porcentaje siempre es más elevado en el caso de mujeres mayores.

4 La muestra de mujeres mayores de sesenta y cinco años para la encuesta de 2019 fue del $24,6 \%(n=2357)$ del total de mujeres entrevistadas.
La comparación con parejas pasadas muestra que las mujeres mayores tienen indicadores de prevalencia claramente inferiores respecto a las más jóvenes, pero muy superiores a los existentes con su pareja actual, lo que indica que las rupturas de pareja pueden estar relacionadas con estas violencias sufridas. La menor prevalencia en parejas pasadas debe ponerse en relación con la estabilidad de las parejas en mujeres mayores, estabilidades muy vinculadas a la situación económica y al proveedor fundamental de la aportación económica llevada a cabo, tradicionalmente, por la figura del varón.

A la luz de estos datos de la Macroencuesta 20195, puede concluirse que las mujeres mayores han ocultado la violencia, en mayor medida que las mujeres de menor edad. Los datos que arrojan las encuestas nos muestran esta invisibilidad en términos de baja prevalencia. A la vez, se constata en términos cuantitativos también el bajo índice de acceso que han tenido o están teniendo estas víctimas a diferentes apoyos institucionales, su baja demanda de atención de servicios, tanto en denuncias ante la policía o los juzgados, como ante los servicios sociales, tal y como concluyen los resultados de las dos últimas macroencuestas realizadas para el conjunto de España, algo que también se refleja en los datos recogidos por los sistemas de atención especializados en atención a víctimas de violencia de género tanto a nivel nacional como comunitario.

${ }_{5}^{5}$ Según datos de la macroencuesta de la Delegación de Gobierno para la Violencia de Género (2020), las mujeres mayores han ocultado la violencia vivida en la pareja en mayor medida que las mujeres de menor edad, en términos de denuncia penal o solicitud de ayuda formal o no formal; en dichos aspectos presentan porcentajes inferiores al resto de mujeres. En total, el $65 \%$ de mujeres mayores que han sufrido cualquier tipo de violencia ha denunciado este hecho o buscado ayuda formal o informal, frente al 85,6\% del resto (16 a 64 años). 
En la Comunidad Autónoma del País Vasco (CAPV), los datos muestran una incidencia baja en el acceso a los servicios y recursos por parte de este colectivo de víctimas, siendo los colectivos del rango de edad media los de mayor acceso, como recoge el último informe publicado por Emakunde (Supergintza Elkartea, 2020).

La macroencuesta sobre violencia contra la mujer de 2019 sitúa en el 23,4\% la prevalencia de mujeres mayores de sesenta y cinco años que sufre o ha sufrido violencia de sus actuales parejas o pasadas. Sería admisible que en cualquier de las instituciones que ofrecen atención directa, acompañamiento e intervención, las cifras de mujeres mayores atendidas debieran acercarse a esa proporción del conjunto de mujeres atendidas, pero las cifras quedan extremadamente lejos de ella, por lo que es clara su invisibilidad, tal y como se refleja en las Tablas 2, 3 y 4.
Los datos disponibles en la CAPV muestran con claridad la infrarrepresentación de las mujeres en todos los servicios ofertados desde las tres Administraciones intervinientes. El último informe publicado por Emakunde (Supergintza Elkartea, 2020), muestra que la mayor parte de mujeres atendidas en su globalidad pueden rondar entre los veintiuno y los cincuenta años (hay diferencias en función de los recursos, pero el grueso de la atención se centra en estas edades) y apenas existen atenciones en mayores de sesenta y cinco años. Es especialmente llamativa la ausencia en servicios especializados de intervención psicológica, en atención jurídica, en atención primaria o en urgencias hospitalarias. No acuden, no son visibles, no solicitan ayuda o son ocultadas bajo otras demandas y atenciones.

Tabla 2. Proporción de mujeres víctimas de violencia mayores de sesenta y cinco años atendidas por servicios del Gobierno Vasco, 2015-2019 (porcentaje sobre el total de mujeres atendidas)

\begin{tabular}{|c|c|c|c|c|c|}
\hline Víctimas mayores de sesenta y cinco años atendidas por servicios del Gobierno Vasco & 2015 & 2016 & 2017 & 2018 & 2019 \\
\hline Seguridad y protección Ertzaintza & 4,82 & 4,83 & 4,63 & 3,8 & 4.2 \\
\hline Atención primaria & 1,41 & 1,49 & 12,50 & 13,6 & 13 \\
\hline Urgencias hospitalarias & 4,15 & 3,35 & 3.11 & 3,3 & 3 \\
\hline Centro coordinador de violencia contra las mujeres (CCVCM) & 8,29 & 2,50 & - & 2,5 & 2,5 \\
\hline Baremación adicional en las promociones de viviendas de protección oficial en alquiler & 2,08 & 1,42 & 0,0 & 1,0 & 1.6 \\
\hline Asignación directa de viviendas en alquiler en casos graves y excepcionales & 0,00 & 0,00 & 0,0 & 0,00 & 0,00 \\
\hline Prestación económica de pago único a mujeres víctimas de violencia de género & 1,33 & 0,70 & 1,18 & 2,4 & 0,5 \\
\hline
\end{tabular}

Fuente: Elaboración propia a partir de los informes de Emakunde (2016-2020).

Tabla 3. Proporción de mujeres víctimas de violencia mayores de sesenta y cinco años atendidas por las diputaciones forales en Euskadi, 2015-2019 (porcentaje sobre el total de mujeres atendidas)

\begin{tabular}{|c|c|c|c|c|c|}
\hline Víctimas mayores de sesenta y cinco años atendidas por las diputaciones forales en Euskadi & 2015 & 2016 & 2017 & 2018 & 2019 \\
\hline Acogida inmediata para mujeres víctimas & 1,1 & 2,41 & 2,33 & 2,3 & 2,3 \\
\hline Centros forales residenciales para mujeres víctimas & 1,98 & 2,15 & 0,71 & 0,0 & 0,0 \\
\hline Asesoramiento jurídico de las situaciones de maltrato doméstico y agresiones sexuales a mujeres & 5,69 & 5,46 & 5,58 & 3,5 & 1,0 \\
\hline Atención psicológica de las situaciones de maltrato doméstico y agresiones sexuales a mujeres & 4,73 & 3,48 & 3,60 & 4,70 & 4,70 \\
\hline Otros programas especializados* & 7,41 & 6,58 & 6,35 & 2,40 & 4,10 \\
\hline
\end{tabular}

Fuente: Elaboración propia a partir de los informes de Emakunde (2016-2020).

Tabla 4. Proporción de mujeres víctimas de violencia mayores de 65 años atendidas por los municipios en Euskadi, $2015-2019$ (porcentaje sobre el total de mujeres atendidas)

\begin{tabular}{|c|c|c|c|c|c|}
\hline Víctimas mayores de sesenta y cinco años atendidas por los ayuntamientos & 2015 & 2016 & 2017 & 2018 & 2019 \\
\hline Servicios sociales de base & 5,23 & 3,96 & 3,32 & 5,30 & 4,40 \\
\hline Servicio de alojamiento, pisos de acogida & 3,17 & 0 & 0 & 1,20 & 2,90 \\
\hline $\begin{array}{l}\text { Servicio de atención psicológica de las situaciones de maltrato doméstico y agresiones sexuales } \\
\text { a mujeres* }\end{array}$ & 9,74 & 5,04 & 3,65 & 3,60 & 6,00 \\
\hline $\begin{array}{l}\text { Servicio de asesoramiento jurídico de las situaciones de maltrato doméstico y agresiones } \\
\text { sexuales a mujeres }\end{array}$ & 5,61 & 7,69 & 5,66 & 5,90 & 8,10 \\
\hline 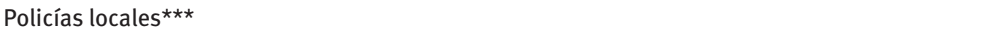 & - & - & 3,8 & - & - \\
\hline
\end{tabular}

Fuente: Elaboración propia a partir de los informes de Emakunde (2016-2020).

* Ayuntamientos de Bizkaia y Gipuzkoa.

** Ayuntamientos de Bizkaia.

$\star \star \star$ Vitoria-Gasteiz, Bilbao y San Sebastián. 
Esta falta de acceso a los recursos, además de mantener a las víctimas ocultas y faltas de apoyo y protección, invita a cuestionar la idoneidad en términos de atención a su individualidad, necesidades y posibilidades. La cuestión de fondo es conocer la razón real por la que no acuden, si responde a que los recursos no son adecuados para sus necesidades, o a que son realidades ocultas y ocultadas.

Por otro lado, si observamos los datos estadísticos que ofrecen los informes elaborados para conocer el estado de la cuestión, puede observarse que no refleja el impacto de la violencia machista en este rango de edad ${ }^{6}$. Si se toman como base de estudio los datos de atención a víctimas en función de la edad y en relación con el tipo de violencia sufrida, puede destacarse que, conforme reflejan estos datos, la violencia de género propiamente dicha aparece en menor medida que la violencia intrafamiliar, esta confluencia con otras violencias es un aspecto diferencial en el caso de las víctimas mayores; otra cuestión que queda sobradamente reflejada es la baja atención a la violencia sexual, lo que indica la poca visibilidad que se tiene de esta tipología de violencia sufrida por la mujer mayor.

Para ello, mostramos una muestra de los datos relativos a los recursos forales y municipales que se ofrecen en la CAPV y que han trascendido en los informes emitidos oficialmente obtenidos a través de la recogida de datos institucional de aquellos recursos que los emiten, y que incluyen el rango mayor de 65 años y tipo de violencia7. (Tabla 5)

${ }^{6}$ Esto se debe además de un bajo acceso a los recursos, a un bajo conocimiento de la atención real; en dichos gráficos estadísticos, en ocasiones el rango de edad de mayores de 65 años (única etapa del ciclo vital delimitada numéricamente por la Organización Mundial de la Salud) se presenta aglutinada con edades anteriores, más de sesenta años, por ejemplo, o bien acotada a un intervalo delimitado de la tercera edad. 0 , en ocasiones, aparecen las atenciones a mujeres mayores víctimas de violencia machista en el ámbito de pareja sumadas a otro tipo de violencia sufrida en este rango de edad, como por ejemplo violencia doméstica o intrafamiliar de género. Por otro lado, también es de destacar el hecho de que, en ausencia de datos concretos de atención en este rango de edad, no se refleja la ausencia, o bien no figura en el grafico este rango de edad.

7 En relación con servicios ofrecidos por Gobierno Vasco, se muestran los datos ofrecidos por la Ertzaintza dado que son los que recogen o publican este rango de edad. El Servicio Especializado de Información y Atención a Mujeres Víctimas de Violencia Doméstica o por Razón de Sexo (SATEVI) de Gobierno Vasco, aunque sí recoge la tipología de violencia en mujeres mayores, delimita el inicio del rango en" mayores de 60 años" por lo que no se ajusta a nuestra variable de estudio. De las mujeres atendidas por el SATEVI, en 2018, un 10,3\% según el informe (Emakunde 2019), eran mujeres mayores de 60 años; aunque es un dato significativo tratándose de ese rango tan elevado de edad, no podemos conocer qué porcentaje de ese 10,3\% pertenecía a mujeres mayores de 65 años. En 2019, el SATEVI atendió un total de 2.645 víctimas (Emakunde, 2020) incrementándose un $9,79 \%$ con respecto al año 2018; sin embargo, las mujeres de más de 60 años, en 2019 , representan el 4,8\% del total, de las cuales un $4,8 \%$ fue atendida por violencia pareja o expareja, el $11,6 \%$ violencia intrafamiliar y se atendió un $0,0 \%$ por violencia sexual en mujeres mayores de 60 años. Todos estos datos siempre han de ser tomados con cautela, puesto que en un $52,6 \%$ de los casos se desconoce la edad. El Servicio de Asistencia a la Víctima (SAV) del Gobierno Vasco no remite datos relativos a la edad, no obstante, se observa (Emakunde, 2020) que en 2019 tramitaron 2.263 expedientes. El 69,4\% (1.570) eran expedientes tramitados por violencia de género (el $71,8 \%$ del total de casos); violencia intrafamiliar, el 20,6\% (467) y delitos contra la libertad sexual el 9,9\% (226). No obstante, hay que tomar nueva-
Otra de las cuestiones que explica la invisibilización de estas víctimas y que constituye una suerte de discriminación es que existe una tendencia a homogenizar un modelo de víctima a nivel de imaginario social, como se refleja tanto en estudios internacionales (Straka y Montminy, 2006) como nacionales (Gracia Ibáñez, 2015; Meneses-Falcón y Charro-Baena, 2019) los cuales coinciden en afirmar que una de las razones que explica la invisibilización de las violencia de género contra las mujeres mayores es debida a la permanencia de estereotipos o "mitos" los cuales asocian ser víctima con ser joven y con hijas/os, con lo cual quedan excluidas las mujeres de mayor edad. Esta invisibilidad es motivo de especial preocupación en tanto en cuanto la situación de vulnerabilidad en que se encuentran estas víctimas aumenta el impacto y riesgo para ellas.

Habiendo mostrado la incidencia de la invisibilidad de la situación de victimización de las mujeres mayores, nos adentramos ahora en conocer de manera holística la interacción de las circunstancias que rodean dicha victimización con el ánimo de comprender la dimensión específica en su totalidad.

\section{Victimas mayores e interseccionalidad}

\subsection{Dimensiones de análisis intervinientes desde la variable edad}

El factor edad es determinante a la hora de interpretar las circunstancias que interseccionan en la situación de violencia. Es importante hacer visible esta realidad que ha permanecido oculta para poder integrar sus necesidades en la respuesta social e institucional al objeto de ofrecer una respuesta acorde y equitativa en función de sus derechos.

En el caso que nos ocupa, las mujeres mayores víctimas de violencia de género en el ámbito de pareja presentan unas características diferenciales en relación con víctimas de otras edades. La edad las coloca, como indica Crenshaw (2002), entre varios ejes de subordinación:

- La posición socioeconómica de la mujer mayor.

- La subjetividad femenina supeditada al hombre y al "vivir para los demás".

- La intersección entre sexismo y edadismo ${ }^{8}$.

Por ello, hay que observar la violencia de género que sufren estás mujeres desde la complejidad de las interacciones de su circunstancia y las desigualdades que coexisten, las cuales condicionan la visión y atención a la victimización, tanto a la propia víctima

mente con cautela los datos, ya que una mujer puede tener abierto más de un expediente.

${ }^{8}$ El edadismo es la discriminación por edad. Hace referencia a todos los comportamientos inadecuados y prejuicios hacia las personas, vinculados a su edad avanzada. Según la Organización Mundial de la Salud, tiene efectos negativos sobre la persona: afecta a la autoestima directamente. 
Tabla 5. Distribución de mujeres víctimas de violencia atendidas en recursos del Gobierno Vasco, las diputaciones forales o los ayuntamientos, según tipología y edad, en Euskadi, 2018-2019 (en porcentaje)

\begin{tabular}{|c|c|c|c|c|c|c|c|c|c|c|c|}
\hline Atención & Tipología & & $\begin{array}{l}\ll 14 \\
\text { años }\end{array}$ & $\begin{array}{l}14-17 \\
\text { años }\end{array}$ & $\begin{array}{c}18-20 \\
\text { años }\end{array}$ & $\begin{array}{l}21-30 \\
\text { años }\end{array}$ & $\begin{array}{l}31-40 \\
\text { años }\end{array}$ & $\begin{array}{l}41-50 \\
\text { años }\end{array}$ & $\begin{array}{l}51-64 \\
\text { años }\end{array}$ & $\begin{array}{c}\geq 650 \\
\text { años }\end{array}$ & Total \\
\hline \multirow{6}{*}{$\begin{array}{l}\text { Gobierno Vasco } \\
\text { Seguridad } \\
\text { (Ertzaintza) }\end{array}$} & \multirow{2}{*}{ Pareja/expareja } & 2018 & 0,0 & 0,0 & 5,8 & 25,7 & 33,0 & 24,9 & 6,9 & 1,5 & 100 \\
\hline & & 2019 & 0,1 & 2,1 & 5,6 & 26,0 & 32,0 & 24,8 & 7,6 & 1,8 & 100 \\
\hline & \multirow{2}{*}{ Intrafamiliar } & 2018 & 20,5 & 10,7 & 5,0 & 9,1 & 7,3 & 15,4 & 18,8 & 13,2 & 100 \\
\hline & & 2019 & 17,0 & 9.2 & 4,7 & 8,8 & 8,7 & 17,2 & 21,0 & 13,4 & 100 \\
\hline & \multirow{2}{*}{ Sexual } & 2018 & 20,8 & 20,1 & 15,0 & 19,5 & 9,8 & 10,6 & 3,4 & 0,8 & 100 \\
\hline & & 2019 & 16,4 & 22,3 & 13,0 & 21,3 & 11,6 & 10,4 & 2,8 & 2,1 & 100 \\
\hline \multirow{2}{*}{\multicolumn{2}{|c|}{ s/Totales }} & 2018 & 6,1 & 5,5 & 6,5 & 21,7 & 25,7 & 21,7 & 9,0 & 3,8 & 100 \\
\hline & & 2019 & 5,1 & 5,5 & 6,1 & 22,0 & 25,3 & 21,9 & 9,9 & 4,2 & 100 \\
\hline \multirow{8}{*}{$\begin{array}{l}\text { Servicios forales } \\
\text { Acogida inmediata }\end{array}$} & \multirow{2}{*}{ Pareja/expareja } & 2018 & 0,0 & 0,0 & 5,4 & 29,1 & 36,9 & 21,7 & 4,9 & 2,0 & 100 \\
\hline & & 2019 & 0,0 & 0,5 & 5,3 & 29,8 & 35,1 & 23,9 & 4,3 & 1,1 & 100 \\
\hline & \multirow{2}{*}{ Intrafamiliar } & 2018 & 0,0 & 0,0 & 12,5 & 62,5 & 0,0 & 12,5 & 0,0 & 12,5 & 100 \\
\hline & & 2019 & 0,0 & 0,0 & 30,8 & 7,7 & 15,4 & 0,0 & 23,1 & 23,1 & 100 \\
\hline & \multirow{2}{*}{ Sexual } & 2018 & 0,0 & 0,0 & 20,0 & 40,0 & 0,00 & 20,0 & 20,0 & 0,0 & 100 \\
\hline & & 2019 & 0,0 & 0,0 & 10,0 & 20,0 & 40,0 & 30,0 & 0,0 & 0,0 & 100 \\
\hline & \multirow{2}{*}{ Otras Violencias } & 2018 & - & - & - & - & - & - & - & - & - \\
\hline & & 2019 & 0,0 & 0,0 & 0,0 & 66,7 & 33,3 & 0,0 & 0,0 & 0,0 & 100 \\
\hline \multirow{2}{*}{\multicolumn{2}{|c|}{ s/Totales }} & 2018 & 0,0 & 0,0 & 6,0 & 30,6 & 34,7 & 21,3 & 5,1 & 2,3 & 100 \\
\hline & & 2019 & 0,0 & 0,5 & 7,0 & 28,5 & 34,1 & 22,4 & 5,1 & 2,3 & 100 \\
\hline \multirow{8}{*}{$\begin{array}{l}\text { Servicios forales } \\
\text { Apoyo psicológico }\end{array}$} & \multirow{2}{*}{ Pareja/expareja } & 2018 & 0,2 & 1,0 & 2,3 & 14,3 & 33,9 & 30,6 & 17,7 & 5,0 & 100 \\
\hline & & 2019 & 0,0 & 1,4 & 2,0 & 15,6 & 30,6 & 31,7 & 12,8 & 5,8 & 100 \\
\hline & \multirow{2}{*}{ Intrafamiliar } & 2018 & 13,0 & 14,6 & 9,2 & 15,1 & 12,4 & 15,7 & 14,6 & 5,4 & 100 \\
\hline & & 2019 & 11,5 & 16,7 & 9,0 & 14,1 & 9,6 & 11,5 & 19,2 & 8,3 & 100 \\
\hline & \multirow{2}{*}{ Sexual } & 2018 & 2,1 & 12,8 & 16,0 & 27,7 & 24,5 & 11,7 & 5,3 & 0,0 & 100 \\
\hline & & 2019 & 1,9 & 10,9 & 11,5 & 16,7 & 14,7 & 14,7 & 3,8 & 1,3 & 100 \\
\hline & \multirow{2}{*}{ Otras Violencias } & 2018 & - & - & - & - & - & - & - & - & - \\
\hline & & 2019 & 0,0 & 0,0 & 20,0 & 20,0 & 40,0 & 20,0 & 0,0 & 0,0 & 100 \\
\hline \multirow{2}{*}{\multicolumn{2}{|c|}{ s/Totales }} & 2018 & 1,8 & 3,3 & 15,2 & 30,7 & 27,7 & 4,7 & 12,2 & 4,7 & 100 \\
\hline & & 2019 & 1,3 & 3,9 & 3,7 & 16,0 & 27,8 & 28,8 & 12,8 & 5,7 & 100 \\
\hline \multirow{8}{*}{$\begin{array}{l}\text { Ayuntamientos } \\
\text { Servicios sociales } \\
\text { de base }\end{array}$} & \multirow{2}{*}{ Pareja/exparea } & 2018 & 0,4 & 1,0 & 3,7 & 21,1 & 34,8 & 25,3 & 8,9 & 4,8 & 100 \\
\hline & & 2019 & 0,2 & 0,8 & 3,4 & 22,0 & 31,8 & 27,5 & 10,3 & 3,9 & 100 \\
\hline & \multirow{2}{*}{ Intrafamiliar } & 2018 & 13,2 & 11,8 & 11,8 & 10,3 & 8,8 & 14,7 & 11,8 & 17,6 & 100 \\
\hline & & 2019 & 16,7 & 10,6 & 16,7 & 9,1 & 13,6 & 6,1 & 15,2 & 12,1 & 100 \\
\hline & \multirow{2}{*}{ Sexual } & 2018 & 6,6 & 18,4 & 17,1 & 25,0 & 17 & 7,9 & 3 , & 3,9 & 100 \\
\hline & & 2019 & 1,28 & 10,3 & 15,4 & 33,3 & 7,7 & 12,8 & 5,1 & 2,6 & 100 \\
\hline & \multirow{2}{*}{ Otras Violencias } & 2018 & - & - & - & - & - & - & - & - & - \\
\hline & & 2019 & 50,0 & 0,0 & 0,0 & 0,0 & 50,0 & 0,0 & 0,0 & 0,0 & 100 \\
\hline \multirow{2}{*}{\multicolumn{2}{|c|}{ s/Totales }} & 2018 & - & - & - & - & - & - & - & - & 100 \\
\hline & & 2019 & 1,8 & 1,8 & 1,47 & 21,6 & 22,9 & 25,6 & 10,4 & 4,4 & 100 \\
\hline
\end{tabular}

Fuente: Elaboración propia a partir de los informes de Emakunde (2019-2020). 
como a su entorno social y profesional. Estos ejes vienen determinados por lo que podemos llamar variables internas o endógenas y variables externas o exógenas:

- Variables internas o endógenas. Aspectos socioeducativos y aspectos bio-psico sociales (ciclo vital).

- Variables externas o exógenas. Influencia entorno social, influencia del entorno familiar e influencia del entorno profesional.

La observación y toma de conciencia desde la interseccionalidad de estos aspectos y cómo influyen sobre su situación, percepción y margen de maniobra, nos muestran el ejercicio de poder que se ejerce sobre la víctima, tanto desde la estructura social como en términos de agencia. Es clave mostrar su individualidad, ya que tanto su identidad como el proceso vital en el que se ha desarrollado la violencia están marcados por el contexto social en que ha nacido y se ha mantenido. La concurrencia del espacio de su individualidad con el espacio de la familia e instituciones confluye y es determinante en la situación de violencia que sufren las mujeres mayores de sesenta y cinco años por la forma en que se interrelacionan.

Comenzaremos acercándonos al detalle refiriendo el peso del proceso de socialización para las víctimas mayores, las cuales están sufriendo en el presente la incidencia del pasado. Con ello comprenderemos cómo se vehiculan vulnerabilidades y nuevas formas de discriminación y maltrato que intereseccionan sobre la propia victimización, como muestra esta imagen de efectos cronológicos.

A continuación, ampliaremos diferentes dimensiones y veremos cómo esta connivencia de factores opera entre sí posicionando a la víctima en una situación de especial vulnerabilidad.

\subsection{Identidad subyugada}

Las mujeres que nacieron en la primera mitad del siglo pasado construyeron su identidad en un contexto en el que el sometimiento, el control y la humillación hacia las mujeres, por parte de los hombres, era algo normalizado, no sorprendía; eran situaciones legitimadas sobre las que la sociedad no intervenía, más bien todo lo contrario: se imponía desde diferentes agentes socializadores. La infantilización de las mujeres fue un proceso normalizador; incluso los varones adolescentes podían tener más ascendencia en la toma de decisiones familiares que la madre. Esta normalización ha favorecido que la víctima no se identifique como tal, generando con el paso del tiempo mayor normalización y cronificación.

\section{ASPECTOS INTERNOS SOCIOEDUCATIVOS}

Proceso de socialización Sistema de creencias Imperativos de género
+ Factor edad genera
- Mantenimiento de los mandatos de género

- Normalización/baja identificación

- Identidad subyugada

\section{ASPECTOS INTERNOS BIO-PSICO-SOCIALES}

Consecuencias de la violencia machista
+ Factor edad

genera
- Cronificación

- Indefensión/dependencias

- Efectos en la salud física y psicológica

- Mayor vulnerabilidad

\section{ASPECTOS EXTERNOS, ENTORNO SOCIOFAMILIAR E INSTITUCIONAL}

+ Factor edad genera
- Rol social actual de la mujer mayor (cuidados)

- Edadismo/maltrato institucional

- Confluencia con otras violencias

- Mayor invisibilidad 
Las mujeres de estas generaciones se educaron en un sistema con pocas o ninguna libertad, conservador y reaccionario, el cual marcaba muy de cerca sus pasos, delimitando sus deseos, sueños y su progreso económico y social. Como señala Lagunas (2017), estaban y están presas del modelo de mujer que se imponía: mujer recatada, conservadora y sumisa, para la que el hogar y la familia fueron sus únicos espacios permitidos. La educación de las niñas estaba dirigida a formar mujeres cuyo destino natural era el sacramento del matrimonio y su papel como madre y esposa subordinada al marido, y esto ha favorecido la normalización de esa desigualdad. Y aunque estas mujeres han liderado cambios imprescindibles en la educación de sus hijas e hijos, en la asunción de lo erróneo de estos criterios educativos y su rechazo activo, la forma en la que fueron educadas marca su reacción más íntima, su emocionalidad y las dificultades para autorreconocerse víctimas de violencia machista.

Esta circunstancia, permanente hoy en día, las puede arrojar a una situación de mayor vulnerabilidad, puesto que su sistema de creencias las aboca a mantenerse en el papel en el cual construyeron su identidad de género: buenas esposas, obedientes, abnegadas y facilitadoras de cuidados a la familia, y mantenimiento de la estructura familiar tradicional indisoluble, porque sostienen que mejor mala que sin ella. Esto traspasa incluso a aquellas mujeres más jóvenes entre ellas, que fueron protagonistas de las rupturas culturales de los años sesenta y setenta.

Las mujeres mayores de sesenta y cinco años se han mantenido, por lo general, en segundo plano, han vivido su vida dedicadas exclusivamente a otras personas, lo cual las ha vinculado a ellas y han construido una identidad dependiente de esos mandatos, de modo que sienten que han de mantenerse en pareja, al lado de alguien, dado que es desde donde han construido su identidad, desde el "yo para otros". Este sentimiento del deber del cuidado a los demás está muy presente también en las víctimas, con efectos sobre su capacidad de autocuidado. Esto se refleja en el testimonio de una mujer de sesenta y siete años, recogido en el informe de la Asociación Argituz (2004: 44) la cual recuerda, una agresión grave como el día en que empezó a temer por su integridad y por su vida, lo cual en su relato aparece más ligado a sus obligaciones de cuidado (hacia hijas/s, padres, etc.), que al peligro para ella misma. Así lo expresa:

Me empujó un día desde una pared a la otra, unos 20 metros, bueno y más cosas, muchas humillaciones. Ahí empecé a pensar que cualquier día me echa por las escaleras para abajo. Y ¿qué va a pasar con mis hijos, con mi padre...?

A esto se une el sentimiento religioso cristiano que hoy mantienen estas víctimas mayores y cuyos preceptos para la mujer eran el sacrificio y la resignación cristiana, como se muestra en los siguientes testimonios:
Yo me casé con mi marido porque me dijo que todos los problemas que teníamos eran porque Dios nos estaba castigando por no estar casados?. Yo le pido a Dios todos los días que se muera y eso es terrible porque soy creyente, pero me está haciendo tanto daño que yo lo que quiero es que desaparezca ${ }^{10}$.

\section{3. Ética del cuidado y rol social de la mujer mayor}

El rol de cuidadoras de esta generación de mujeres, nacidas antes de 1954, es fundamental y constituye una pieza clave para su identidad, incluso de aquellas que han trabajado. Son las cuidadoras por antonomasia y el pilar fundamental de la reproducción social, han cuidado de sus madres, y padres, suegras/os, maridos, e hijas/os. Estas situaciones están fuertemente arraigadas en el sistema de creencias de estas mujeres por ser "lo que nos ha tocado", "nuestro deber”. Las víctimas de violencia machista en el ámbito de pareja también alargan, como muchas mujeres mayores, esos cuidados actualmente a nietas y nietos, por lo que no podemos pasar por alto esta realidad que hoy se ha dado en llamar síndrome de la abuela esclava, que tan bien describió Guijarro (2001). Este autor señalaba que las mujeres mayores con responsabilidades de cuidado de nietos y nietas pueden ver seriamente comprometida su salud como consecuencia de la interacción entre factores psicológicos y educativos y factores ambientales, como son el estrés familiar excesivo y / o el bajo apoyo social o familiar. Este sistema de opresión al que en ocasiones se ven expuestas, o por el que no son consultadas de forma explícita, pueden sobrepasar las capacidades de las mujeres mayores, pero se sienten obligadas a ello.

Como indica Pérez Ortiz (2005), el cuidado de nietos y nietas puede verse como un instrumento de control sobre las mujeres mayores. El hecho de mantener y/o devolver a las mujeres mayores a las obligaciones reproductivas supone un refuerzo del modelo patriarcal, manteniéndolas en un espacio privado y desfavoreciendo su autorrealización en otros espacios, como refleja Pérez Ortiz (2012). Siguiendo las afirmaciones de Maestre-Miguel et al., (2012) el papel de las abuelas, en su faceta más instrumental, pueden ser un mecanismo informal de conciliación de la vida familiar. No obstante, en ocasiones, nadie les ha preguntado si quieren asumir el papel en este nuevo rol cuidador "obligado socialmente". Les viene dado, sin reflexionar sobre cómo se sienten ellas ante este nuevo rol.

En el caso de las mujeres mayores víctimas de violencia, este hecho, además de ser otra forma de abuso añadida por su entorno familiar frente al cual se siente ante la dicotomía entre el sentimiento de felicidad que les da compartir la vida con sus

\footnotetext{
9 Testimonio recogido en el informe de la Fundación Ede (2010: 34). ${ }^{10}$ Testimonio recogido en el informe de la Fundación Ede (2010: 37).
} 
nietas/os y la sobrecarga del cuidado, se le añade la resistencia a disolver de algún modo la estructura familiar ante la inseguridad de no poder mantener esa atención en forma económica, cuidados, etc.

Como refleja el estudio del Instituto de la Mujer (2018) y el informe de la Fundación Ede (2012), las mujeres mayores sienten una mayor presión social cuando existe, por parte de hijas/os, la necesidad de que actúe como cuidadora o colabore en la atención económica de nietas/os, y/o es cuidadora de hijos divorciados/separados que han regresado al domicilio, e incluso el hijo puede ser un maltratador de su pareja. Este aspecto condiciona en sentido negativo para la toma de decisiones en beneficio de mantener el sistema familiar y en el estudio de la Delegación de Gobierno para la Violencia de Género (2019) se resalta esta circunstancia como situación de vulnerabilidad adicional.

Para la víctima mayor de sesenta y cinco años que se encuentra en la circunstancia anteriormente expuesta, al rol de cuidadora se suma su propia situación de maltrato machista por parte de su pareja.

El rol de cuidadoras de estas mujeres y la responsabilidad del bienestar de su familia supera su percepción de ser víctima de violencia; es tan determinante que incluso los cambios psicológicos o el declive en la salud de su agresor (u otro miembro de la familia) son una influencia para elegir permanecer al lado del agresor (Meneses-Falcón y Charro-Baena, 2019), perpetuando con ello la victimización. Por tanto, todo este aspecto del yugo del cuidado se convierte, además, en otro hándicap para la toma de decisiones a la hora de una posible ruptura con la situación de violencia.

\subsection{Dependencia intelectual}

Esta restricción anteriormente señalada al ámbito doméstico tiene consecuencias hoy en día para la víctima en términos de crecimiento personal relativo a su formación y capacitación, y genera nuevas dependencias. En general, si bien es verdad que hay mujeres de estas edades que ya fueron a la universidad y/o desarrollaron niveles profesionales, la media de nivel educativo y de cualificación de las mujeres mayores está por debajo del nivel educativo medio actual de las mujeres más jóvenes. Esto genera dos situaciones que por sí mismas promueven la desigualdad y la dependencia. Debe recordarse que el nivel educativo implica no solo la instrucción, sino también el acceso a la información, a intercambios de opiniones, análisis y críticas en los contextos que suelen llevar a la reflexión de la influencia de los roles de género, lo cual facilita mayor percepción de los comportamientos violentos (Trujano et al., 2006), así como peor comprensión de sus derechos y desconfianza en la justicia. Este último aspecto tiene especial interés sobre todo cuando es desoído institucionalmente, como indica la Delegación del Gobierno para la Violencia de Género (2020) cuando refiere que algunas mujeres mayores frente al exceso de burocracia que puede suscitar pedir ayuda consideran que no están preparadas para enfrentarse a ello, percibiendo además que en ocasiones se las trata como si debieran estar informadas de todo.

Por otro lado, y como consecuencia de la falta de formación e información, anteriormente expuesta, las mujeres mayores que son víctimas no han accedido con normalidad a la toma de decisiones, ni a la práctica de gestiones económicas y/o administrativas en el espacio público, gestiones reservadas a sus maridos y, cuando es el caso, sus agresores. Ello impide que las víctimas conozcan a día de hoy las dinámicas de estos procedimientos y dependen de sus maridos $u$ otra persona para llevarlas a cabo o bien no se sienten con la capacidad para realizarlas.

\subsection{Feminización de la pobreza y dependencia económica}

La discriminación económica hacia las mujeres es otra de las grandes discriminaciones que han sometido a las mujeres muy dependientes de sus congéneres varones, sean maridos, padres 0 hermanos. La ausencia de capacidad en la toma de decisiones sobre su propio patrimonio, e incluso sus ingresos, ha ido lastrando a generaciones de mujeres que debían someterse a los dictados masculinos. Aun hoy en día, es un factor que aumenta la vulnerabilidad, por lo que tiene sus efectos sobre la situación de violencia en el ámbito de pareja que sufre. Debe recordarse que el trabajo asalariado de las mujeres en las décadas de los años cincuentasesenta en España estaba sometido a restricciones jurídicas tras el matrimonio. Algunas mujeres debían abandonar el espacio laboral al contraer matrimonio, o las que lo han mantenido, en algunos casos, han llevado a cabo trabajos auxiliares precarios, entendidos como complementarios al del varón y principalmente como empleadas de hogar o en el sector servicios sin ningún tipo de protección legal, o como apoyo al negocio familiar.

Este hecho, unido a las restricciones que el mandato doméstico y dominación por parte de su agresor que ha sufrido ha mantenido a la víctima fuera del ámbito laboral, dependiente económicamente de su marido. Esta discriminación laboral puede haber desembocado en que, a día de hoy, dependan económicamente de su agresor para vivir, o bien perciben pensiones contributivas cuyo importe es insuficiente para llevar a cabo una vida autónoma, lo que las posiciona en una situación de objetiva vulnerabilidad económica.

Este aspecto es de calado, pues se trata de una mujer cuya edad la excluye de la población activa, lo cual afecta considerablemente a la idea de proyectar un futuro próspero en términos 
económicos. Esta cuestión es clave en términos de modelos de intervención con víctimas de violencia contra la mujer, dado que restringe el margen de maniobra que se necesita para generar procesos de empoderamiento, tal como se persigue y espera en la intervención con víctimas más jóvenes.

\subsection{Las consecuencias de la violencia de género}

Los efectos de la violencia en mujeres mayores, en términos de gravedad, no difieren de otros grupos de edad. No obstante, presentan diferencias significativas cuando se tiene en cuenta la edad y la exposición prolongada a la situación. La continuidad durante décadas es una característica de este tipo de violencia en esta franja de edad, como refieren (Meneses-Falcón y Charro-Baena, 2019). Además de las ya descritas, como dependencia económica, mayor grado de indefensión aprendida para adaptarse a la relación abusiva, etc., cabe señalar, en el caso de las victimas mayores, los efectos de la violencia sobre la salud que, según Álvarez García et al. (2016), multiplican el impacto por tratarse de un mantenimiento de largo recorrido en el tiempo, favoreciendo el declive de la salud ya que se asocia al proceso biológico de envejecimiento.

En este sentido, se ha observado que pueden tener más problemas de salud, ansiedad y somatizaciones y aumentar la ingesta de fármacos - antidepresivos y ansiolíticos- (Stein y Barrett-Connor, 2000) con un impacto psicopatológico evidente que produce un descenso de la calidad de vida, un aumento de problemas psicosomáticos y un aumento en las consultas de médicos/as de familia (Sarasua et al., 2007). En este sentido, es propio decir que en las mujeres mayores los efectos de la violencia pueden no ser adecuadamente diagnosticados por las y los profesionales de la salud, ya que se tienden a atribuir a enfermedades ligadas a la edad (Eisikovits y BandWinterstein, 2015).

Algunas/os autores/as refieren que el estrés sufrido por dicha situación puede impactar a nivel psiconeuroinmunológico de las mujeres mayores (Baker et al., 2009), así como presentan daño en la subjetividad (Serrano Hernández, 2013).

El análisis de los datos para la población general de la Encuesta Nacional de Salud (2018), (análisis de sexo y franja de edad) y referidos concretamente a las mujeres mayores de sesenta y conco años, se observa que las mujeres víctimas de género manifiestan una peor salud, valorándola como "mala" o "muy mala" en cinco puntos porcentuales más que las medias de la población femenina de la misma edad. Esto produce una condición muy singular en las mujeres mayores, que retroalimenta el daño sufrido. Como refleja el estudio de la Delegación de Gobierno para la Violencia de Género (2020), al impacto de la violencia continuada en la salud se le une en esta etapa vital el deterioro asociado al envejecimiento, el cual puede resultar progresivamente discapacitante. Esto revierte, además, en una mayor vulnerabilidad ante una eventual nueva agresión.

\subsection{Confluencia con otras violencias}

Al tratarse de mujeres mayores, la situación de violencia puede convivir con otras violencias que contribuyen a ocultar la violencia de género. La presencia de la violencia doméstica, violencia intrafamiliar de género, o violencia hacia las personas mayores es más habitual de lo que a priori se considera, y oculta unas con otras. Tampoco puede olvidarse de que muchas de ellas son infantilizadas por sus propios hijos e hijas, desautorizando sus decisiones o tomando decisiones por ellas. En este sentido, cabe destacar una situación que pueden sufrir las víctimas cuando existe dependencia física y necesita de cuidados. Suele ser muy común anular su capacidad en la toma de decisiones incluso de asuntos que a ellas les competen. Además, en los casos en que estos cuidados vienen de la mano del agresor, se puede "enmascarar" con estrés del cuidador, desdibujando así la causa del maltrato y enfocando el apoyo hacia el agresor (Celdrán 2013).

Esta realidad, presente en algunas situaciones de violencia en víctimas dependientes, se ha de tener en cuenta desde la perspectiva acertada, ya que, de lo contrario, estaríamos desprotegiendo aún más a la propia víctima.

\subsection{Dificultades específicas para la ruptura asociadas a la edad}

Estas mujeres informan menos de su situación, como se refleja en el estudio del Programa Daphne de la Comisión Europea (Unión de Asociaciones Familiares, s.f.). El 28,1\% de mujeres entre 60 y 79 años manifiesta haber experimentado algún tipo de violencia por parte de su pareja en los últimos doce meses; no obstante, menos de la mitad había informado nunca al respecto, como se desprende de dicho estudio. Esto es una muestra de cómo las víctimas mayores han mantenido su situación en silencio continuado, con el secretismo que preponderaba en la época en que fueron educadas, que las abocaba a mantenerlo en el ámbito privado.

En segundo término, destacamos que las circunstancias adversas que rodean la victimización de las mujeres mayores, y que hemos relatado, conforman una serie de barreras, como ya han sido definidas genéricamente (Beaulaurier et al., 2005) ${ }^{11}$.

\footnotetext{
${ }^{11}$ Se refieren a que esta situación genera una serie de barreras, tanto internas como externas, que dificultan la búsqueda de ayuda por parte de estas mujeres mayores víctimas de violencia de género. Entre las barreras internas, algunos autores (Beaulaurier et al., 2005) señalan cinco tipologías diferentes: (1) el deseo de proteger a la familia y, sobre todo, a los hijos, de la situación; (2) el sentimiento de autoculpa y resignación después de tantos años de violencia familiar; (3) el sentimiento de estar desprotegidas y ser dependientes econó-
} 
Podríamos señalar - por ejemplo- la dependencia económica de la mujer de su pareja (Delgado Álvarez et al., 2007; Zubizarreta et al., 1994), la ausencia de alternativas residenciales viables (Craven, 2003), o la ausencia de apoyos sociales, tanto informales (Cubells et al., 2010) como formales (Zubizarreta et al., 1994). El aislamiento al que se han visto sometidas, unido a la menor red social que suele verse reducida por la muerte de allegados y amistades, genera además sensación de mayor soledad, de forma que, en ocasiones, esto no hace sino acercar a las víctimas a sus agresores, porque al fin y al cabo es lo que han tenido toda su vida.

\subsubsection{Dificultades para denunciar}

A todo lo ya descrito hasta ahora, como la influencia del sistema de creencias en términos de toma de decisiones para la ruptura de la convivencia y el declinar de la salud del agresor, etc., se suma la falta de información sobre sus derechos o bien las dificultades para poder comenzar su vida de cero.

El afrontamiento de cambios puede generar confusión, pero en edades avanzadas la dificultad aumenta. Según Red2Red (2018), el sentimiento de que ya se encuentran en la última etapa de la vida dificulta proyectar un futuro diferente y desean vivir tranquilas el tiempo que les queda. Junto a este deseo de una vida con menos sufrimientos coexiste el miedo a lo desconocido, a empezar de nuevo, a gestionar cualquier tipo de cambio (estado civil, entorno familiar, domicilio, etc.). A algunas mujeres, la interposición de la denuncia o el divorcio les genera sentimientos de fracaso a estas edades, o bien inseguridad; este aspecto tiene especial incidencia por su impacto en términos económicos y de vivienda.

Por otro lado, en ocasiones a tenor de la opresión a que han sido sometidas y el efecto que ha tenido esto sobre su capacidad de maniobra, genera en ellas una persistencia del locus de control externo, que incluso en ocasiones sitúan en manos de Dios, como se refleja en el siguiente testimonio:

\section{[...] cuando Dios se lo lleve... yo viviré. ${ }^{12}$}

En este sentido, incide sobremanera el papel de las hijas e hijos en términos tanto de apoyos para la propia víctima (Meneses et al., 2018; De Miguel, 2015; IAM, 2018). También puede tener un efecto

micamente y socialmente de sus parejas; (4) el sentimiento de desesperanza por un futuro incierto; y (5) el valor del secretismo, común en otras edades -es decir, la idea de que aquello que ocurre en la familia no debe salir de la familia-. Respecto de las barreras externas, se suelen resaltar en la literatura cuatro tipos (Beaulaurier et al., 2007, Celdrán 2013): (1) el poco apoyo que las mujeres mayores creen que van a recibir por parte del resto de la familia; (2) la presión religiosa y el valor del matrimonio en su comunidad; (3) la desconfianza que a estas mujeres les suscita el sistema judicial y los profesionales especializados en violencia de pareja; y (4) los pocos recursos que existen en su comunidad pensados para su problemática.

${ }^{12}$ Testimonio recogido en el informe de la Fundación Ede (2010: 37). de cortapisa a la hora del mantenimiento de la protección de la mujer hacia las hijas y los hijos en caso de que se tuvieran que hacer cargo de su padre, con lo que supone este hecho sobre la victimización sufrida al unísono por esta descendencia ya independizada del núcleo familiar. Como bien se visualiza en el testimonio de esta víctima:

Que se rompa una estructura familiar de unos padres de cuarenta años no es lo mismo que ahora, mis hijas se ven que van a tener que hacerse cargo de su padre. ${ }^{13}$

Algunas autoras ponen el énfasis en elementos vinculados con la edad de las mujeres y, en relación con ello, con la duración del proceso de violencia. Aspectos tales como que si no llegaron a la decisión de poner fin a la relación siendo más jóvenes, es particularmente complejo que logren hacerlo siendo mayores cuando la perspectiva de esperanza de vida es inferior y resulta particularmente difícil imaginarse iniciando una nueva vida (Bhatia y Soletti, 2019). 0 cuestiones relativas a que las alternativas reales son menores que en el caso de mujeres jóvenes (porque la salud ya no es buena, porque encontrar empleo es más difícil cuanto mayor es la edad de la mujer, porque el aislamiento es en ocasiones realmente intenso, etc.). (Gracia Ibáñez, 2015 y 2016; Hightower et al., 2006).

\subsection{Edadismo/maltrato institucional}

La variable edad en la mujer víctima de violencia de género debe ser considerada a efectos de adecuarnos a su circunstancia, como hemos venido reflejando. Sin embargo, puede ocurrir que, a efectos de atender a una víctima mayor, prevalezca la edad sobre el género en forma de discriminación edadista. En estos casos, la mujer es vista como mayor antes que como mujer. Esto tiene consecuencias para la atención, pudiéndose considerar que no merece la pena afrontar cualquier tipo de proceso de ruptura. Este proceder puede dejar a la víctima de violencia de género mayor de sesenta y cinco años sin atención. En ocasiones puede ocurrir, de acuerdo con la evaluación realizada por el proyecto Breaking the Taboo II de la Comisión Europea (Messelis y Moreels, 2010), que se produzca una asimilación por parte de las y los profesionales de los servicios sociales y de salud entre maltrato a la persona mayor y violencia de género sufrida por la mujer mayor ejercida por la pareja. Por eso es tan primordial para la detección y para la toma de conciencia de la propia víctima el rol ejercido por las figuras profesionales que las atienden.

En este sentido, con el fin de no incurrir en ninguna desatención institucional, como bien afirma Susana Enciso (2013), psicóloga clínica experta en intervención con víctimas de violencia de género, la sociedad debe dar a las victimas mayores de sesenta y cinco años respuestas y ayudas reales,

\footnotetext{
${ }^{13}$ Testimonio recogido en el informe de la Fundación Ede (2010: 31).
} 
ofrecerles un lugar en el que no haya que partir de cero a una edad tan avanzada. Ya en el año 2003, un informe del Ararteko-Defensor del Pueblo Vasco concreta, en relación con las necesidades no cubiertas de las mujeres maltratadas, que el $59,3 \%$ de las entrevistadas considera que habría necesitado algo más. Existe una carencia de recursos adaptados a mujeres mayores que sufren violencia de género y respuestas específicas desde un enfoque interseccional (Gracia Ibáñez, 2015).

En la Figura 2, a modo de resumen de este análisis interseccional mostrado, se recoge de manera gráfica la visión holística de esta realidad aludida, al objeto de tener una mirada general que dé una idea instantánea de la posible globalidad e idiosincrasia en que se desarrolla la propia situación de violencia.

Con estos aspectos expuestos hasta ahora, hemos pretendido ofrecer una imagen de la realidad de las víctimas desde una perspectiva interseccional. Para finalizar, presentamos una pequeña aproximación a algunos retos a los que nos enfrentamos como sociedad y como figuras profesionales para transformar esta realidad.

\section{Retos acordes a la mirada interseccional}

Como expresa Dorothy Smith (2005), el estudio del papel de las instituciones en la vida de las personas es fundamental, ya que permite superar los límites entre las divisiones sociológicas entre lo macro y lo micro. Siguiendo esta idea, no podemos dejar de identificar a las mujeres mayores como víctimas o supervivientes, en este caso silenciosas, de la violencia de género. No existe un modelo de víctima, no existe un tipo unívoco de superviviente, no existen patrones a los que ajustarse, porque la diversidad de ellos es enorme y lo único que tienen en común estas mujeres es justamente ser víctimas. Por ello, no pueden ser consideradas victimas "no perfectas" porque no se adecúan a los criterios legales ni a los perfiles sociales y estándares de comportamiento

\section{La concurrencia de su individualidad histórica con su entorno familiar e institucional vehicula vulnerabilidades y nuevas formas de discriminacion y maltrato que intereseccionan sobre la propia victimización}

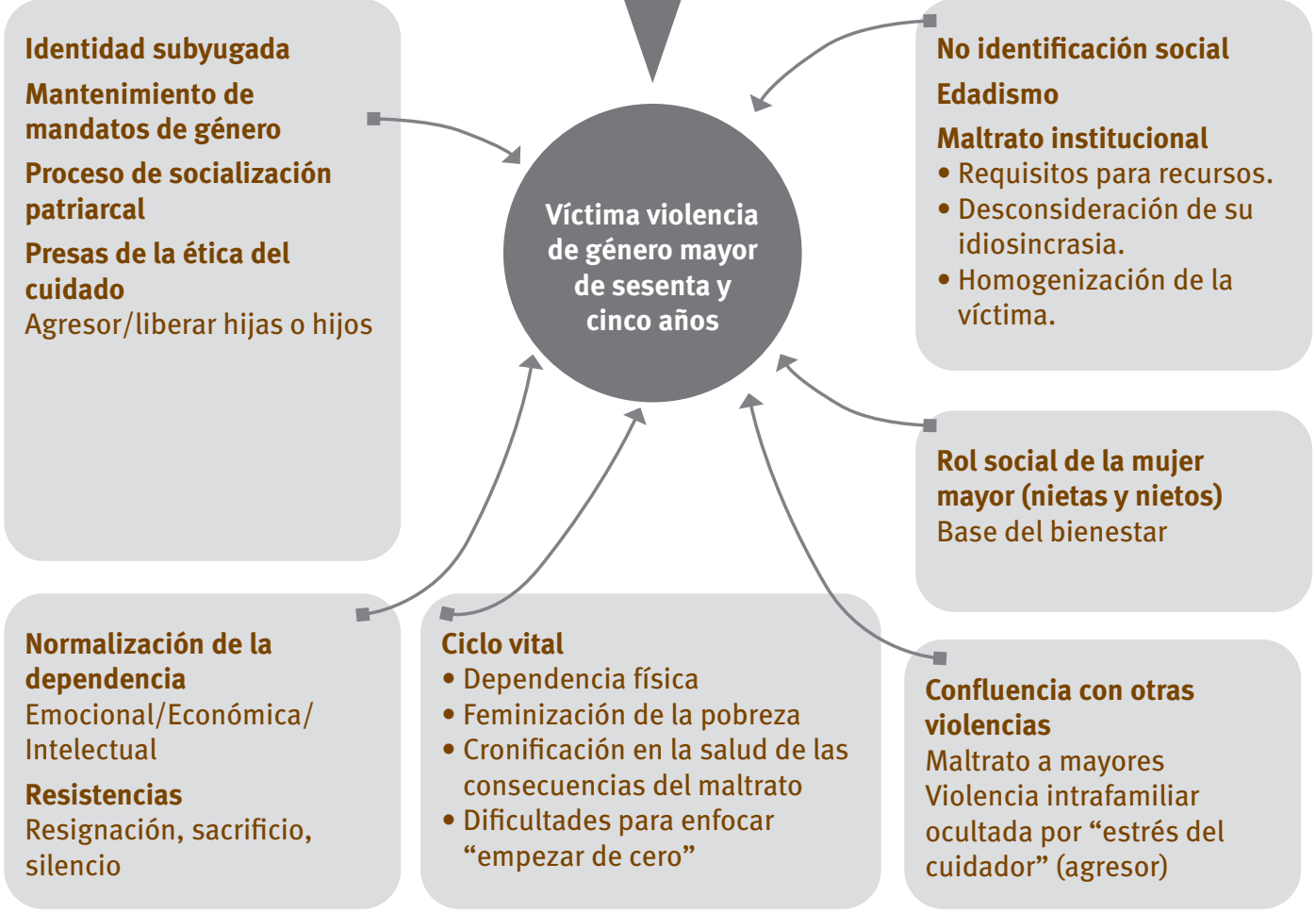


de una víctima de violencia de género (MacDowell, 2013).

En el estudio realizado en la Comunidad Autónoma de Madrid por Meneses-Falcón y Charro-Baena (2019), se concluyó que la edad de las víctimas fue el principal obstáculo para que las necesidades de muchas mujeres mayores de sesenta y cinco años estuviesen atendidas, e indicó que los modelos de intervención que tradicionalmente se vienen utilizando con mujeres víctimas de violencia de pareja no fueron los más apropiados para ellas; no todas las mujeres pueden requerir el mismo apoyo o la misma intervención. En este mismo estudio se observó que la falta de respuesta adecuada obligó al médico de atención primaria a paliar las consecuencias de la violencia que vivían con la prescripción de psicofármacos, cuando lo que realmente precisaban era una intervención psicosocial adaptada a sus necesidades.

Los modelos tradicionales dirigidos a las mujeres que sufren violencia en el ámbito de pareja deben ser revisados porque no incluyen a las mujeres mayores. Habrá que repensar, por tanto, este modelo de atención teniendo en consideración, además, que las mujeres mayores víctimas de violencia, debido a su proceso vital y a su entorno social actual, presentan una serie de desigualdades. Sería aconsejable la observación de cómo este entramado de desigualdades, probablemente no de forma sumatoria, sino desde una mirada que analice en sentido biopsicosocial, puede estructurar la vida en torno a la propia situación de violencia de una mujer mayor. Esto ayudará a interrogar esta realidad desde diferentes frentes, evitando sesgos y realizando, por tanto, una aproximación más honesta que revertirá en visibilizarla en toda su onda expansiva y acercarnos a proporcionar una solución acorde que aminore en la medida de lo posible las violencias que enfrenta esta mujer mayor.

Si tomamos como guía las recomendaciones de la Convención sobre la Eliminación de toda forma de Discriminación contra la Mujer (CEDAWC, 1999 y 2010) se han de promover desde los presupuestos gubernamentales las políticas sociales, el apoyo a la investigación y cambios normativos. En este sentido, se ha de promover la investigación dirigida a conocer la prevalencia, las necesidades y dificultades de estas mujeres mayores de sesenta y cinco años víctimas de violencia de género; con ello facilitaremos su detección atención y, por tanto, contribuiremos a la no perpetuación de su situación.

Es, por tanto, imprescindible diseñar e introducir los indicadores y mecanismos necesarios que permitan el conocimiento de la incidencia de la variable edad, cuya concurrencia resulta generadora de situaciones de discriminación múltiple en los diferentes ámbitos de intervención. Con ello no se vulnerarán sus derechos a una atención adaptada a su situación en términos equitativos, de lo contrario estaríamos priorizando las necesidades, experiencia e intereses de unas personas, léase mujeres víctimas de violencia de género, en detrimento de un subgrupo de mujeres que sufren, y llevan sufriendo años en silencio, la violencia de género en el ámbito de pareja. 
ÁLVAREZ GARCÍA, M; SÁNCHEZ ALIAS, A.M. y BOJÓ, P. (coords.) (2016): Manual de atención psicológica a víctimas de maltrato machista, Colegio Oficial de Psicología de Gipuzkoa.

ARARTEKO (2003): Respuesta institucional a la violencia contra las mujeres de la CAPV, serie Informes Extraordinario al Parlamento Vasco, VitoriaGazteiz, Ararteko.

ASOCIACIÓN PRODERECHOS HUMANOS ARGITUZ (2015): Informe de identificación de necesidades y obstáculos encontrados por las mujeres víctimas de violencia de género del área rural de Bizkaia en el acceso efectivo a los servicios y prestaciones de apoyo, atención y justicia, Bilbao, Departamento de Acción Social de la Diputación Foral de Bizkaia.

BAKER, M.W.; LACROIX, A.Z.; WU, C.; COCHRANE, B.B.; WALLACE, R. y WOODS, N.F. (2009): "Mortality risk associated with physical and verbal abuse in women aged 50 to 79 ", Journal of the American Geriatrics Society, 57(10), pp. 1.7991.809 .

BAZO, M.T. (2001): "Negligencia y malos tratos a las personas mayores en España", Revista Española de Geriatría y Gerontología, vol. 36, nํㅜ 1, pp. 8-14.

BEAULAURIER, R.L.; SEFF, L.R.; NEWMAN, F.L. y DUNLOP, B. (2005): “Internal barriers to help seeking for middleaged and older women who experience intimate partner violence", Journal of Elder Abuse \& Neglect, 17(3), pp. 53-74.

- (2007): "External barriers to help seeking for older women who experience intimate partner violence", Journal of Family Violence, vol. 22, $\mathrm{n} \cong 8$, pp. 747-755.

BHATIA, P. y SOLETTI, A.B. (2019): "Hushed Voices: Views and Experiences of Older Women on Partner
Abuse in Later Life", Ageing International, vol. 44, n- 1, pp. 41-56.

BONOMI, A.E.; ANDERSON, M.L.; REID, R.J.; CARRELL, D.; FISHMAN, P.A.; RIVARA, F.P. y THOMPSON, R.S. (2007): "Intimate partner violence in older women", The gerontologist, 47(1), pp. 34-41.

CELDRÁN, M. (2013): “La violencia hacia la mujer mayor: revisión bibliográfica”, Papeles del psicólogo, 34(1), pp. 57-64.

CHO, S.; CREENSHAW, K. y MCCALL, L. (2013): “Toward a field of interesectionality studies: Theory, applicationes, and praxis", Signs, 38, pp. 785 810.

COMITÉ PARA LA ELIMINACIÓN DE LA DISCRIMINACIÓN CONTRA LA MUJER (CEDAW) (1999): Consideration of reports submitted by States parties under article 18 of the Convention on the Elimination of All Forms of Discrimination against Women, CEDAW/C/PRK, Naciones Unidas.

- (2010): Recomendación sobre las mujeres de edad y la protección de los derechos humanos, CEDAW /C/GC/27, Naciones Unidas.

CRAVEN, Z. (2003): Battered Women Syndrome, serie Topic Papers, Australian Domestic and Family Violence Clearinghouse.

CRENSHAW, K. (2002): “Critical Race Studies. The first decade: Critical reflections or 'a foot in the closing door", UCLA Law Review, vol. 49, pp. 1.343-1.372.

- (2012): "Documento para o encontro de especialistas em aspectos da discriminação racial relativos ao gênero", Estudos Feministas, 10(1), p. 171.

CUBELLS SERRA, J.; CALSAMIGLIA MADURGA, A. y ALBERTÍN CARBÓ, P. (2010): "Sistema y Subjetividad: 
la invisibilización de las diferencias entre las mujeres víctimas de violencia machista", Quaderns de Psicologia, 12(2), pp. 195-207

DE MIGUEL LUKEN, V. (2015): Macroencuesta de violencia contra la mujer 2015. Madrid, Ministerio de Sanidad, Servicios Sociales e Igualdad.

DELEGACIÓN DEL GOBIERNO PARA LA VIOLENCIA DE GÉNERO (2020), Macroencuesta de violencia contra la mujer (2019), Madrid, Ministerio de Igualdad. Gobierno de España, 〈https://violenciagenero. igualdad.gob.es/violenciaEnCifras/ macroencuesta2015/Macroencuesta2019/ home.htm>.

DELGADO ÁlVAREZ, C.; IRAEGUI TORRALBA, A.; MARQUINA TORRES, L.; MARTÍN TABERNERO, M.F.; PALACIOS VICARIO, B.; PLAZA SÁNCHEZ, J.F.; SENDÍN MELGUIZO, P.P., PÉREZ GRANDE, M.D. y SÁNCHEZ GÓMEZ, M.C. (2007): “Patrones de masculinidad y feminidad asociados al ciclo de la violencia de género", Revista de Investigación Educativa, 25(1), pp. 187-218.

EISIKOVITS, Z. y BAND-WINTERSTEIN, T. (2015): “Dimensions of suffering among old and young battered women", Journal of Family Violence, 30(1), pp. 49-62.

ENCISO, S. (2013): "Sanidad, justicia y psicología en la violencia de género" [presentación en mesa redonda], Encuentro por una Sociedad Libre de Violencia contra las Mujeres, Cursos de Verano de El Escorial, Universidad Complutense de Madrid.

FISHER, B.; ZINK, T.; RINTO, B.; REGAN, S.; PABST, S. y GOTHELF, E. (2003): “Guest editors' introduction. Overlooked issues during the golden years: Domestic voilence and intimate patner voilence against older women", Violence against Women, vol. 9, nํㅜ12, pp. 1.409-1.416.

FUNDACIÓN EDE (2010): La variable edad en la intervención contra las mujeres víctimas de violencia de género, Vitoria-Gasteiz, Servicio Central de Publicaciones del Gobierno Vasco.

- (2012): Mujeres víctimas de violencia de género: vivencias y demandas, Vitoria-Gasteiz, Servicio Central de Publicaciones del Gobierno Vasco.

- (2016): Datos en relación con el alcance de la atención a las mujeres víctimas de violencia en la CAPV. Análisis de la información, Emakunde-Instituto Vasco de la Mujer, <https://www.emakunde. euskadi.eus/contenidos/informacion/ violencia_evaluacion_informes/es_def/ adjuntos/datos_alcance_atencion_mujeres_ victimas_violencia_capv_2016.pdf`.

- (2017): Datos en relación con el alcance de la atención durante el 2016, a las mujeres víctimas de violencia en la CAPV. Análisis de la información, Emakunde-Instituto Vasco de la Mujer, <https://www.emakunde.euskadi.eus/ contenidos/informacion/violencia_evaluacion_ informes/es_def/adjuntos/datos_alcance_ atenci\%C3\%B3n_2016_mujeres_victimas_ violencia_capv.pdf».

- (2018): Datos en relación con el alcance de la atención durante 2017 a las mujeres víctimas de violencia en la CAPV. Análisis de la información, Emakunde-Instituto Vasco de la Mujer, <https:// www.emakunde.euskadi.eus/contenidos/ informacion/violencia evaluacion informes/ es_def/adjuntos/2017_informe_recursos.pdf>.

- (2019): La respuesta a víctimas de la violencia contra las mujeres en la CAE. Datos 2018, EmakundeInstituto Vasco de la Mujer, shttps://www. emakunde.euskadi.eus/contenidos/ informacion/violencia_evaluacion_informes/ es_def/adjuntos/2018.respuesta_violencia_ mujeres.pdf〉.

GRACIA IBÁÑEZ, J. (2015): “Una mirada interseccional sobre la violencia de género contra las mujeres mayores”, Oñati Socio-legal Series, 5(2), pp. 547-569.

- (2016): "Una panorámica sobre la violencia familiar y de género contra las mujeres mayores", Aequalitas, 38, pp. 45-50.

GUIJARRO, A. (2001): El síndrome de la abuela esclava. Granada, Grupo editorial universitario.

HIGHTOWER, J; SMITH, M.J.G. y HIGHTOWER, H.C. (2006): "Hearing the voices of abused older women", Journal of Gerontological Social Work, 46, pp. 205-227.

LAGUNAS, A.C. (2017): “La Falange es un modo de ser (mujer): discursos e identidades de género en las publicaciones de la Sección Femenina (1938-1945)", Historia y política: Ideas, procesos y movimientos sociales, 37, pp. 91120.

MACDOWELL, E. (2013): “Theorizing from Particularity: Perpetrators and Intersectional Theory on Domestic Violence", Journal of Gender, Race and Justice, 16 (2).

MCCALL, L. (2005): "The complexity of intersectionality", Signs, 30, 1.771-1.800.

MENESES, C. (coord.) (2018): La violencia de género en la pareja o la expareja de mujeres mayores de 60 años, Madrid, Universidad de Comillas, 〈http:// hdl.handle.net/11531/34999».

MENESES-FALCÓN C y CHARRO-BAENA B. (2019): “¿Se debe cambiar la intervención para las mujeres mayores de 65 años víctimas de violencia de su pareja?", Atención Primaria, vol. 51, ํㅜㄱ, pp. 458-459.

MESSELIS, E. y MOREELS, A. (2010): Breaking the Taboo II - Developing and Testing Tools to Train-theTrainer, 〈http://www.btt-project.eu/fileadmin/ btt/PDFs/Final_Report_Belgium_29092010. pdf>.

MINISTERIO DE SANIDAD, CONSUMO Y BIENESTAR SOCIAL (2018): Encuesta Nacional de Salud España 2017, Madrid, Ministerio de Sanidad, Consumo y Bienestar Social.

MOUTON, C. et al. (2010): "Psychosocial effects of physical and verbal abuse in postemenopausal women"; Annals of Family Medicine, 8 (3), pp. 206-213.

PARLAMENTO EUROPEO (2012): Resolución del Parlamento Europeo, de 2 de febrero de 2012, sobre el programa Daphne: logros y perspectivas futuras, 2011/2273 (INI), <https://www. europarl.europa.eu/doceo/document/TA-72012-0027_ES.htmls.

PÉREZ ORTIZ, L. (2005): “La protección social a la vejez”, en SANCHO CASTIELLO, M. (coord.): Las personas 
mayores en España. Informe 2004. Datos estadísticos estatales y por comunidades autónomas, tomo I, Madrid, Imserso, pp. 205327.

- (2012): “La protección social a la vejez”, en SANCHO CASTIELLO, M. (coord.), Las personas mayores en España. Informe 2006. Datos estadísticos estatales y por comunidades autónomas, tomo I, colección Estudios, serie Documentos Estadísticos, n- 22.008, Madrid, Imserso.

PURTSCHERT, P. y MEYER, K. (2010): “Die Macht der Kategorien: kritische Überlegungen zur Intersektionalität”, Feministische Studien, 28(1), 130-142.

RED2RED (2018): La violencia de género contra las mujeres mayores en la población aragonesa, Instituto Aragonés de la Mujer.

SARASUA, B.; ZUBIZARRETA, I.; ECHEBURÚA, E., y DE CORRAL, P. (2007): "Perfil psicopatológico diferencial de las víctimas de violencia de pareja en función de la edad", Psicothema, 19(3), pp. 459-466.

SERRANO HERNÁNDEZ, C. (2013): “Un estudio sobre los efectos de la violencia de género en el desarrollo psíquico de las mujeres" [tesis doctoral], Universidad de Deusto.

SLEAP, B. (2017): Tenemos los mismos derechos. ¿Qué dicen las mujeres adultas mayores sobre su derecho a la no discriminación, a la igualdad, a vivir libres de violencia, abuso y negligencia en la vejez?, Londres, HelpAge International, <https://www. helpage.org/silo/files/tenemos-los-mismosderechos.pdf〉.
SMITH, D. (2005): Institutional Etnografy: A Sociology for People, Altamira Press.

STEIN, M.B. y BARRETT-CONNOR, E. (2000): "Sexual assault and physical health: Findings from a population-based study of older adults", Psychosomatic Medicine, 62(6), pp. 838-843.

STRAKA, S.M. y MONTMINY, L. (2006): “Responding to the needs of older women experiencing domestic violence", Violence Against Women, 12 (3), pp. 251-267.

SUSPERGINTZA ELKARTEA (2020): La respuesta a víctimas de la violencia contra las mujeres en la CAE. Datos 2019, Emakunde-Instituto Vasco de la Mujer, <https://www.emakunde.euskadi.eus/ contenidos/informacion/violencia_evaluacion_ informes/es_def/adjuntos/2019.informe recursos_atencion.pdf>.

TRUJANO, P.; NAVA, C.; TEJADA, E. y GUTIÉRREZ, S. (2006): "Estudio confirmatorio acerca de la frecuencia y percepción de la violencia: el VIDOFyP como instrumento de evaluación y algunas reflexiones psicosociales", Intervención Psicosocial, 15 (1), pp. 95-11, 〈http://scielo. isciii.es/scielo.php?script=sci_arttext\&pid=S11 $3205592006000100007 \& \operatorname{lng}=e s \& n r m=i s 0>$.

UNIÓN DE ASOCIACIONES FAMILIARES (s.f.): Proyecto Daphne: Stop a la violencia contra las mujeres mayores, <https://unaf.org/inicio/proyectoeuropeo-daphne-stop-a-la-violencia-contra-lasmujeres-mayores/>.

ZUBIZARRETA, I.; SARASÚA, B.; ECHEBURÚA, E.; DE CORRAL, P.; SAUCA, D. Y EMPARANZA, I. (1994): "Consecuencias psicológicas del maltrato doméstico", en ECHEBURÚA, E.: Personalidades violentas, Madrid, Pirámide, pp. 129-152. 